\title{
Women, the Knowledge Society and ICT Access in the Reindeer Grazing Areas
}

\author{
Maria Udén
}

\section{Introduction}

This paper is about inclusion in the prosperous "winner" networks and practices, caught by the term "knowledge society". ${ }^{1}$ It tells about some people and a location in the Arctic rims of the European Union. The process presented can be described as enacted ambitions for knowledge society inclusion. Among the people involved there have been researchers and professionals of several different nationalities and ethnic backgrounds. But, the Sámi, as represented by the local community engaged in the process, are central. The case study started with affirmative action for Sámi women in Jokkmokk, northwest Sweden, and ended up in future Internet research on a European arena. The Sámi is an indigenous people of northern Scandinavia and northwest Russia. As several of the Sámi groups, the Sámi in this Jokkmokk case study are semi-nomadic reindeer herders. Living and travelling in remote areas, where reliable telecom or broadband are not at hand, their situation as business owners and as citizens is strained. This happens at the same time as a public discourse says that we now have access anywhere and at any time.

A basic assumption in this paper is that increased scale and quality of inclusion in the knowledge society is a sensible goal for promoting the general economic development of a society as well as for those who are, at start, marginal. This thought fits with the spirit of this case study and, as also displacement can be caught through a border phenomenon, together with the inclusion quest, it makes an analytically robust starting point. Of course, the term "knowledge society" is a theoretical concept. The different results that people have tried to

1 Acknowledgement: The research leading to these results has received funding from the European Community's Seventh Framework Programme (FP7/2007-2011) under grant agreement $\mathrm{n}^{\circ} 223994$. 
achieve throughout the course of the Jokkmokk case study have been of more concrete nature. In the course of the text, the case study and its context are established. Initially, affirmative action and equal opportunities were the motivating factors, and one might say that this is still true, but along the way entrepreneurship and technology development have become the tools. Or, are they perhaps the goals? Notably, the same women who started as affirmative action workers in their local community have been driving in both processes. To gather the various themes that arise from this situation where gender, ethnicity, technology and knowledge development meet, it is useful to think in terms of intersectionality. An intersectionality notion is developed in this article, intertwined with theory about the routes to knowledge society inclusion. Information and communication technology (ICT) is studied in relation to gender, location and ethnicity.

The material of the case study has been collected since 2001, using ethnographic and participatory research methodology. Importantly, the paper reflects the author's experience of furthering and at several occasions being executive manager of the projects from which the case study evolved (cf. Lindberg/Udén 2008). This can be described in terms of action research, but can also be viewed as an expression of routine practice in university-based knowledge development. A senior researcher involved in research and development co-operation with non-university actors is a given candidate for leading the projects through which the co-operation is channelled.

\section{Routes to knowledge society inclusion}

If the aim is knowledge society inclusion, how is this achieved? And, what is a knowledge society? These two questions can be addressed jointly. One technique to address challenges for knowledge society inclusion is to take stance against the "success stories" of economies already thriving. Starting from the examples of such achieved successes, David and Foray consider the following characteristics decisive for a knowledge economy (cf. David/Foray 2002):

(1) The acceleration of knowledge production with the emergence of knowledge-based communities, i.e. "networks of individuals striving, first and foremost, to produce and circulate new knowledge".

(2) The rise of intangible capital at macroeconomic level, basically the human capital, meaning that the decisive ability is "to create new knowledge and ideas and incorporate them in equipment and people". 
(3) Growing speed of innovation including both formal and layman environments in the efforts, while innovation comes close to being the sole means to survive and prosper in highly competitive and globalised economies.

(4) The revolution in instruments of knowledge where technologies for knowledge and information production and dissemination, among other capacities, offer remote access, enormous quantities of information, and enhancement of creative interaction.

Besides comparing with already achieved successes, the issue can be addressed via experience from societies and nations that are engaged in processes towards inclusion. Mongolia's path towards the knowledge society was investigated by Johnson et al. (cf. Johnson et al. 2005). This study is of particular interest for the Jokkmokk case study, as nomadism as well as remote location are shared factors for both. The analysis of Johnson et al. emphasises the "four pillars of the knowledge society" (cf. Johnson et al. 2005, p. 217):

(1) ICT and connectivity: The backbone of a knowledge society is a welldeveloped, well-maintained and affordable information infrastructure that allows access to and manipulation of the digital economy;

(2) Usable content: The information available should be affordable, timely, relevant, readily assimilated, and in a language users can understand.

(3) Infrastructure and deliverability: The new digital or dematerialised economy is underpinned by a materialised and top-heavy infrastructure comprised of airports, railways, roads, trucks, warehouses, and physical addresses of people. A dematerialised economy without a physical infrastructure is of little use and can even create unmet expectations.

(4) Human intellectual capability: The development of human capital facilitates development and economic growth. A knowledge society needs people who can create as well as utilise knowledge to ensure not only sustainability, but also prosperity.

Neither of the above referred standpoints is unique in its conclusions. Instead, they were chosen for this paper because of the clear differences in their respective analysis. Their respective views on physical access and infrastructure are the opposite. One analysis puts this first, the other last. But, while there is dissonance there is also concord between them. One aspect common to both is that neither addresses gender. This is of interest as women's conditions are not obviously proceeding towards the better in the knowledge society. In a report pub- 
lished by Orbicom, the International Network of UNESCO Chairs in Communication, Huyer and Hafkin, set the scene:

"Worldwide the capacity of women to engage in the knowledge society is grossly underdeveloped and under-utilized. Women are at risk of becoming increasingly marginalized in the knowledge society, where much more than access to and use of information technology is at stake. In the knowledge society women need access not only to new technologies but also to education, entrepreneurship and employment opportunities, and the ability to participate fully in knowledge-based activities" (Huyer/Hafkin 2007: 2).

Gender theorists accordingly pursue that there is no automatically emancipating power in the progress of the knowledge (or information) society. The Indian activist Anita Gurumurthy, founder of the Bangalore-based organisation IT for Change, writes:

"New paradigms do reproduce old hegemonies and thus there are undoubtedly many mutations to old hegemonies that can keep feminists busy, agitated and as overworked today as in our industrial age preoccupations. The IS [Information Society] paradigm does sit over existing structures of power [...]" (cf. Gurumurthy 2006: 2).

Old hegemonies, old values, are so to speak input variables in the negotiations that take place when ICT is implemented and knowledge society processes evolve (see e.g. Mörtberg et al. 2003). From Simone de Beauvoir onwards, the feminist tradition has been concerned with the "others" or "boundary makers" of modernity and with the fates these "others" face. We think of "the sexualized other, also known as women, the ethnic or racialized others and the natural environment" (cf. Braidotti 2006: 32). Intersectionality theory aims to catch that in reality people are not present in society as discrete essential identities strictly of one sort or another. This observation is of importance for the Jokkmokk case study. As shown by Hooks (1982), if only one aspect of identity at a time can be accounted for, the reality of the least acknowledged people in society becomes impossible to mirror and to account for in theoretically grounded knowledge.

It has been noted, however, that piling up designations of gender, race, age, and so forth one to another, tends to lock the knowledge produced into merely reproducing the inequalities revealed. For ICT studies, Wamala (2010) presents an alternative to the traditional intersectionality concept. When analysing the results of her field studies in Uganda 2008-2009, Wamala is struck by the fact that the predominant strategy to connote the problem of non-access is to think of it as being user-based. Whether it is with reference to inequalities, or ability, users are constructed as problematic, based on their ethnicity, gender, regional location, or class formation. Wamala's suggestion is to do intersectional analysis of access instead of the people who supposedly "have" or do not "have" it. To clarify Wamala's theory, we can here look at two situations from her field work. 
The first is when Wamala finds herself stranded in a remote countryside, among people whose language she does not speak and to whom she is a stranger. Her mobile phone is of no help. Repeatedly she tries to call her local contact for help but cannot reach him as the connection does not work. The solution is to catch a ride with someone passing by. Fortunately, in the car she stops, a nice and trustable person is sitting. The second example is given by the woman "Nora", whom Wamala interviews. Nora does not own a computer and says in the interview that she does not know how to use the Internet. All the same, it turns out that she regularly uses the Internet to speak with her son, who is overseas. Only that this happens via the help of another person, who has the know-how. Nora is one of the $87 \%$ of Ugandans who in the national statistics constitute the group of "non-users". Wamala is one of the users. But in the situation where she finds herself in an area where the mobile phone does not work, it is obvious that the designation "user" does not follow her around. There is more to it than owning a mobile phone. On the other hand, Nora works around her perceived inabilities and makes use of the Internet through her relations with other people. This, as Wamala points out, is contradictory to the more familiar understanding of access which is confined to a user and his or her technology. To capture the fluid quality of access, Wamala puts forth the concept "non-/access". With this concept, she catches how neither access nor non-access is a constant presence that follows one or the other person. Referring to Cisler (2000) and Warschauer (2003), Wamala finds that access is composed of multi-levelled intersections that, when merging, create moments of access.

\section{The research process}

The research presented in the article started in 2001 and is ongoing at the time of writing (2010) as part of an EU FP7 project (N4C). The academic home has throughout been Luleå University of Technology in Sweden (LTU). The methodology has been inspired by a feminist tradition of working life research and science studies, and the so-called Scandinavian tradition for participative design (cf. Gunnarsson 2006; Mörtberg 1997: 29-60; Mörtberg et al. 2003; Aas 1999). The relatively long period of research has included a number of projects. In these projects, the local actors with whom the first project (WIS) was carried out have, together with some other local actors and a fairly stable and gradually growing group of researchers, in one way or another participated in gender studies on the one hand and computer science on the other. The author's as well as the others' degree and type of involvement have of course varied throughout the process and the different projects (cf. Lindberg/Udén 2008). 
For the author, the first period of the research process was closely linked to the WIS project plan, but was carried out in a separately funded project (see more about WIS below). The research during this early period included much of ethnographic methods with interviews, observation and broad interaction both in the community and with relevant authorities. A photographic documentation of women reindeer herders' work was produced by photographer and reindeer herder Lena Kuoljok-Lind. Cornerstones for the development of research themes and perspectives were the WIS core group meetings with women reindeer herders. Additionally, events and workshops for larger audiences generated input. (cf. Udén 2004, 2007, 2009) A component of interactive methodology was included from the first project plan. This opened up Internet research and development. From this point, project design has been important, and also this type of processes includes interactive and other methods (cf. Gunnarsson 2007). ${ }^{2}$

In later stages, the author has had roles more intertwined with executive tasks and fund raising. Because of the type of relations that occur in this situation, the collection of research material is confined in particular ways. Plenty of documentation is generated, in the form of e-mails, project diary and other documentation. However, the detailed information gained in this role cannot be shared with a public audience as regular research. One reason is that being project manager or coordinator means entering a role which is formally regulated by contracts. Also, the actors who have been present throughout the process are at this point easily identified by the public. Therefore, to a certain degree, what is revealed in this article is only such information that is publicly available. The totality of the process becomes the subject. In the ongoing N4C project (see more about N4C below), certain new information about the ICT use in the Sámi villages of the Jokkmokk area has been collected. However, the main part of the usage data and user feedback is to be collected during the last period of the project, which at the moment of writing is being prepared.

2 An EU Interreg North Calotte project, CroCoPil, built on the idea developed from the WIS process in combination with interests among actors within the Arctic Council Sustainable Development Working Group. The project as such generated user investigations from three Nordic countries. In this project, the author was a co-worker but did not collect any of the data. A result of the need-finding based on focus group interviews and other methods were the CroCoPil concepts (cf. CroCoPil 2010). CroCoPil user investigations and the experiences from the project have contributed to other project designs. 


\section{Reindeer husbandry, women and the community's practices today}

The average population density in Jokkmokk municipality is 0.3 inhabitants per square kilometre and the total population is 5,000 persons. Jokkmokk town, the district centre, counts 4,000 inhabitants and is situated slightly north of the Arctic Circle. The municipality area is $17,735 \mathrm{~km}^{2}$. Jokkmokk is the centre not only for the municipality but also for several reindeer husbandry communities. One of these, Sirges, is the largest in Sweden with 400 members, ten to fifteen thousand reindeer and a total grazing area of $13,370 \mathrm{~km}^{2}$. Sirges' area stretches through parts of Jokkmokk via Boden and Luleå municipalities along the Lule River to the Gulf of Bothnia (cf. County Administrative Board 2010). The industry in Jokkmokk is based on hydropower, forestry and reindeer husbandry. The former two have decreased their numbers of employees since the mid1990s, and reindeer husbandry is again the largest employer (often selfemployment in micro-businesses). The reindeer companies are locally owned, which is not the case for hydro power and much of the forestry. Tourism is also relevant to the local economy. The combination of wilderness, mountain terrain and Sámi culture attracts tourists. In neighbouring municipalities, mining stands forth as economic motor while reindeer husbandry is a traditional livelihood all over the region. This whole area is characterised by a small number of population centres spread in a vast land of forests in the eastern parts and with alpine mountains in the west.

Reindeer herding with its subsidiaries has an ancient history in northern Fenno-Scandia, where it is coupled to the indigenous Sámi population. Sápmi is the Sámi word for the land where Sámi traditionally live and to which Sámi culture is coupled. This land encompasses northern Norway, Sweden and Finland. This population makes about 80,000 to 100,000 of the totally 300 million indigenous people in the world. Together, the different Sámi groups herd a total of up to 800,000 reindeer. ${ }^{3}$ Reindeer herding and nomadism are often, but not always coupled together. A reason for nomadism is that especially large herds benefit from grazing different pasture grounds throughout the year. Today, national legislation, unique to each country, controls the way reindeer herding is organised. In Sweden, reindeer husbandry is an exclusive right of the Sámi. The right to herd reindeer rests upon the conditions of being Sámi and having membership in a Sámi village, or grazing community as the term can also be phrased. The Sámi villages are juridical entities established by the Swedish State as possessors of

3 Figures about Sámi and reindeer herding are collected from Svensk rennäring (1999), Jordbruksverket (2003) and Sametinget (2010). 
rights to use land and water for reindeer pasture and subsidiary livelihood from activities such as fishing and hunting. To each village, a specified territory is designated. Geographically, a Sámi village is not a "village" as one would usually imagine the term, and it has nothing to do with where the villagers actually live. Instead, as the Sirges example shows, the Sámi village can encompass quite a large area. In short, the Sámi village is the organisational basis for regulating the rights to herding reindeer in a given territory (cf. Rennäringslagen 1971).

Though the Sámi villages as communal organisations possess the actual land rights, herding as economic activity is not communal, but organised in private enterprises. In Sweden, reindeer industry is composed of micro-enterprises with the owner as major work force. The usual case is that the only work force supplement is temporary employees and the involvement of family members. The exclusive rights to reindeer husbandry in Sweden being reserved for Sámi can be seen as a measure to protect the indigenous culture. On the other hand, reindeer husbandry is the sole legal ground for Sámi in Sweden to acquire indigenous rights to land and water. Only class one active herders have the full rights necessary for the traditional livelihood in the grazing territories. This premiere status is achieved via apprenticeship with family members and finally, formal acceptance by the Sámi village. The opportunities are however limited. Not all interested can possibly reach full membership. The available grazing is the limiting factor of the reindeer population. This makes that the reindeer of one owner limits the possible size of the other's herd.

The communities included in this case study have their grazing territories broadly speaking along the Lule River, from its springs by the Norwegian boarder to the outlet in the Gulf of Bothnia. Depending on the conditions during winter, the reindeer may be herded from the Norwegian border through the wide forests and eventually over the ice to the islands of the Lule archipelago. The distance of migration can then reach $400 \mathrm{~km}$ one way. But, this is not a goal. If the weather conditions allow grazing, one does not take the reindeer that far. When the yearly cycle is presented to outsiders, the community members tend to start with the occasion in December, when all the reindeer of the village are herded from the mountains to a large coral situated in between winter and summer lands. There, they are separated into smaller herds and then moved to the more confined grazing areas in the forest land. During winter, close surveillance is needed as grazing is scarce. During this period, the herders drive their snowmobiles on surveillance rounds among the reindeer, watching for tracks of animals in the snow (see Figure 1). In April, the reindeer are again herded to the mountains, where the calves are born. At this time, all the reindeer of the village are moved at once and they will graze together throughout the rest of the season. All through the long snow season, the snowmobile allows moving in the unset- 
tled areas at a pace compatible with the requirements of every-day life. At the time of moving the herd to the summer lands, there is still snow in the forests and even more so in the mountains when the caravan reaches there. During the summer months, the need for surveillance is smaller, as there is more grazing and as the reindeer wander in areas far from settlements and industrial activity. During this time, however, herders and as far as possible their families stay in summer camps that are relatively close to the herds. In September, the large coral facility is again used for slaughter. On this occasion, the incomes from herding are eventually generated. The herd is then again let out to graze freely, until it is once more gathered, separated into smaller groups and moved to the forests and possibly the coast, if needed, for winter grazing.

Figure 1: Woman herder by herders' cabin. January 2002

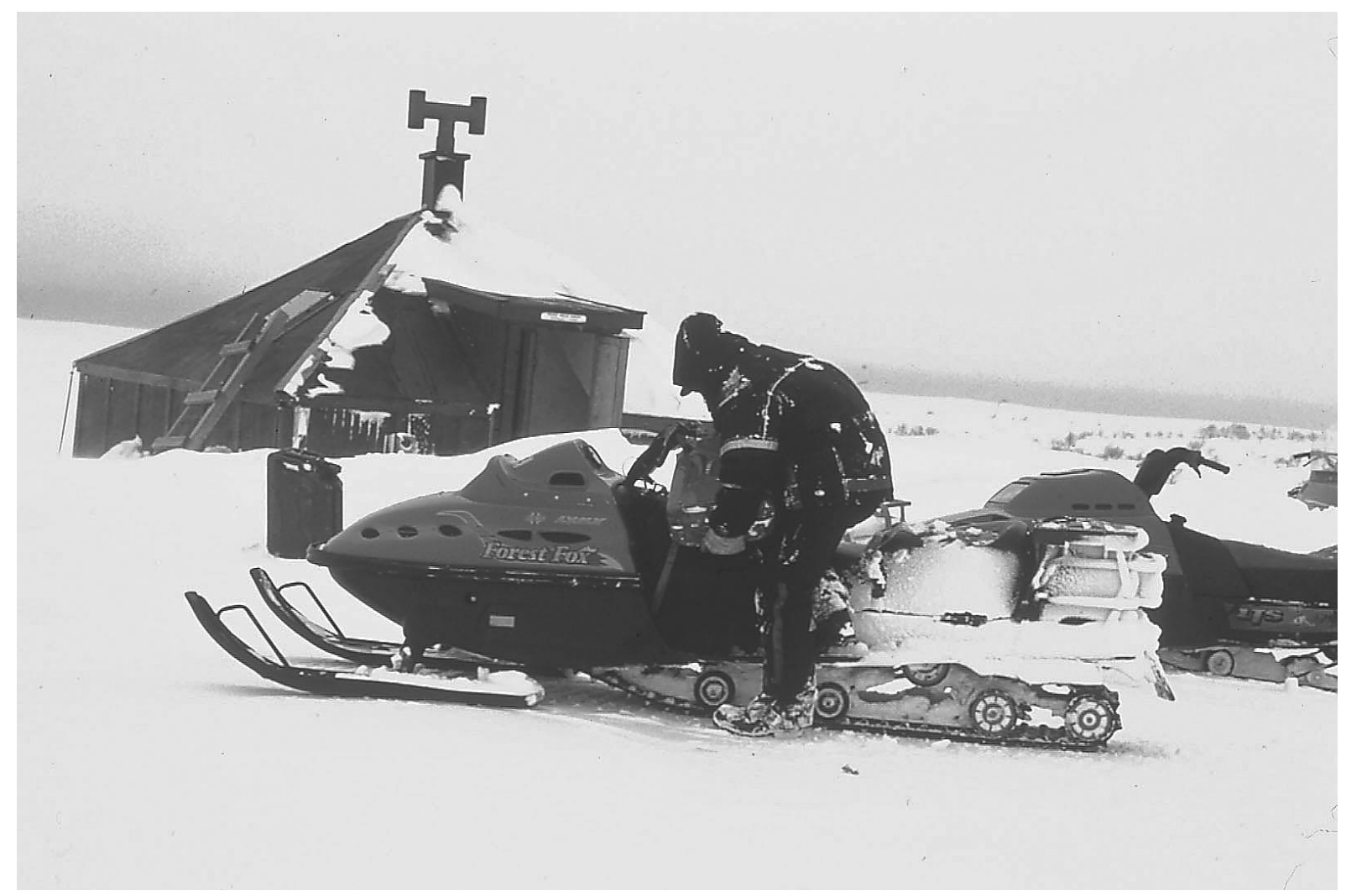

A woman filling petrol in her snowmobile. The picture was taken during the winter season, in January 2002. In the background: a reindeer herders' cabin for shorter stays.

Photo by Lena Kuoljok Lind 
The ways of living are of course not static. The material culture of the indigenous population has changed significantly during the $20^{\text {th }}$ century, as has that of the European society at large. These days, the households do not travel along with the herders and their animals all the year, as was the practice into the early $20^{\text {th }}$ century. Schooling for the children and paid employment for spouses require a more stationary life. Yet, nomadism is still a factual part of community life and the households keep huts and houses in two or often three or up to four steady locations, while they additionally use tipis for the most remote and shortest stays. Along the travel routes, small communal huts are built for the herders to use while moving or watching the herds. Chains of motorised vehicles put herding at pace with the times and create room for the herders to, for instance, spend more time with their families, as it becomes possible to travel distances in a single day that formerly would have taken much longer. Snow mobiles, lorries, motorcycles, and in particular task helicopters are used for transportation and herding. The chain of complementary vehicles effectuates the community's answer to the challenges posed and prospects offered by our times. It is intricately put together in order to fit the change of seasons and the different stages of husbandry practice. For instance, during the snow season, one often sees snowmobiles being transported by cars to reach the rims of the unsettled grazing areas. Where skis were earlier used throughout, one can now drive to a suitable point as far as the roads go, park the car and exchange it for a snowmobile. Nonetheless, travelling and staying beyond infrastructure and settlements remains a main characteristic of the work. This makes the personal performance of the herders decisive for their business results as well as for their health, well-being and even survival while travelling, living and working in harsh and often hazardous conditions (cf. Jernsletten/Klokov 2002).

The reindeer industry is gendered in such a manner that a majority of the reindeer enterprise leaders are men, and the largest herd owners are men. The Swedish average counts one woman business leader out of eight reindeer herding companies. Swedish reindeer industry legislation used to explicitly prohibit the full herder status for women. While the gender specific language was removed in the early 1970's, much of the gender-biased practice remains. As national legislation has coupled herding business leadership to Sámi rights, the gender structure of herding business has significant effects among the Sámi beyond the scope of business itself. Women being marginal in herding affects their options and likeliness to remain in the grazing communities, which hold the legal access to land and water and so make the indigenous lifestyle possible to maintain. It is called for to speak of a deeply consequential discriminatory practice affecting the Sámi women. This practice is found in multiple instances. It is reproduced among Swedish authorities as well as in the communities them- 
selves. Due to the construction of the legislation, the existent discriminatory practice negatively affects women's opportunities not only to make a living in the traditional industry but also to maintain influence in community matters. Depending on the criteria used, $10-25 \%$ of the herders are women. The share of reindeer owners who are women is $30 \%$. However, owning a reindeer is not the same as being a full rights class 1 Sámi village member. The largest herds are owned by men (cf. Amft 2000; Kråik 2002; SCB 2001; Udén 2007, 2009; Åström 2005). This was the context for Woman in the Sámi Village (WIS), which was the first in a series of projects that constitute this case study.

\section{Woman in the Sámi Village}

WIS was an effort to improve women's prospects to remain in the particular husbandry community in Jokkmokk, but it also had connections to women's gender equality activism in Sámi organisations and assemblies. In the project, two women were employed. Both were reindeer herders and first class members of their Sámi village. Activities concerning gender equality had been going on for some years before WIS. However, the woman who worked as WIS project leader had initiated the WIS project as such. She and the woman who came to work with her in WIS have remained a team throughout the process presented here. Already in the planning of WIS, research support from the nearby regional university, Luleå University of Technology (LTU), was invited. A partnership was formed between the local women's team and the gender and technology studies group at LTU where the author of this paper was responsible for driving the process within the research environment. Ergonomics, effective herding methods, organisation and technology use, entrepreneurial development and policy questions were targeted. Besides the obvious steps of engagement with formal and informal conditions that affect women's conditions, including targeting attitudes towards women in the male-dominated herder profession, the project staff and a group of women in the village worked on the development of new routines and adjustment of technical systems to suit the local women and their factual situation. The women were thus aiming at better revenues and more income opportunities. Ergonomic factors for women herders were targeted, and several ideas were launched for more effective herding routines, including new or changed technology use. Promoting entrepreneurial ideas among the women in the community and discussing policy questions of special relevance for women were on the agenda as well. The affirmative action was paired with an ambition to raise the income levels at large. The project workers were positive that unless the economy of husbandry business grows, the opportunity for gender 
equality will in reality never arise (cf. Udén 2008, 2009). Presently, many units generate incomes below the national minimum for sustainable SMEs (Amft 2000; Gustavsson/Johnsson 2000: 45-54; Nordin 2007). Why carry on this challenged livelihood? One woman interviewed during the first research period associated with affirmative action in the village talked about the turn of the seasons and the different conditions, the ways of working and set of tasks that uniquely go together with each season. There is always something to look forward to, she explained. Besides the nowadays rare and deeply satisfactory experiences the nature-based life offers, the nomadic practice remains necessary for the reindeer businesses, as for reproduction of the indigenous culture. ${ }^{4}$

The two WIS staff will continue to be referred to in the further description of the case study below. From the point when ICT became a part of the effort, the Sámi Educational Centre in Jokkmokk and the staff of the Internet portal Same Net became a hub. Same Net as an Internet-enabled forum for Sámi all over Scandinavia was opened already in the 1990's. The first steps were taken by the board of the Swedish Sámi Federation (SSR) in the early 1990's, and the complete portal was available as from 1998, at that point run by the Sámi Educational Centre in Jokkmokk. In the ICT development process of this case study, the Sámi Educational Centre and the Same Net staff have been host for student projects and major project meetings and have kept and managed equipment and web content. The same have also been actively supportive in fund raising, in particular the Same Net staff. While WIS was very much an effort involving several of the women in the community, and especially the women reindeer herders, the efforts and concrete projects after WIS have included varying participants. These have been local men and women, but also researchers from several countries and business owners and entrepreneurs from throughout Scandinavia and recently the European Union. The reason why the two original WIS staff play a particularly important part in the case study is that they have been driving the process from WIS onwards. They are also the link from the first engagement in working life development for women in reindeer herding to the ICT research that followed.

4 For further details about the modern indigenous life of the Sámi in Jokkmokk, see Beach (2001), which is a standard anthropological volume describing the year cycle among these herders. 


\section{From Objective 1 to the Seventh Framework Programme}

In the WIS project description, the significance of technical development was stated as a factor of importance for the promotion of women's opportunities in the herding profession. The significance of the snowmobile became apparent in the WIS core group meetings, and generally in any discussion between the researchers and community members or public servants working with the reindeer industry, the topic of the snowmobile would come up with regard to the question why so few women are active reindeer herders. In formal and informal settings alike, people would talk about the snowmobile as the main obstacle to women's full participation in herding. One and the same statement recurred: "The snowmobile is too heavy for women!" As the snowmobile is indeed the one decisive equipment for the individual herder's competitiveness today, it is a logical conclusion that if women were indeed unable to handle the snowmobile, it would effectively hinder their success as herders. It was agreed among the women herders that, in a number of situations, snowmobile handling was heavy. Nevertheless, they found the idea ridiculous that they at any given moment would be physically inferior to each male herder in the community. Manual labour and physical challenges are always part of the reindeer herder's day. Snow mobile driving is just one part of it. Handling the reindeer, which are only semidomesticated, is one of the tasks where physical strength and endurance is required on top of knowledge and technique. The women found that both attitudes in the community and unfavourable, exclusionary arrangements in work organisation added to forcing them into disadvantageous positions in relation to herding and to the snowmobile and its use (cf. Udén 2004, 2007). Snow mobile driving does bring occupational injuries and accidents at a significant level. It represents a major ergonomic problem for the herders, men and women included. During the WIS project period, one of the women reindeer herders and a man in her near family on separate occasions got injured in snowmobile accidents so that they were hindered for some time from taking part in herding.

While the snowmobile was a central issue during the initial stage of WIS, information and communication technologies (ICT) were only marginal among the topics. This single factor set the process slightly aside from the mainstream industrial development of today. In other respects, the activities and strategies could be recognised as standard methodical development of working routines, business models and dissemination of knowledge, and as such could have been carried out in any European industry or community (in relation to the available resources). Where the implementation of ICT-based solutions would otherwise have been obvious steps, such manoeuvres were of limited interest to this community. This situation, cannot be understood other than in relation to the lack of 
access in the grazing lands, at the very basic level of connectivity, which means that ICT is not available where the actual industrial activity in herding takes place. However, in this matter, a turning point came after the community project "Gender Studies Partnership" had established contact with the university's computer science department. In the spring of 2002, the partnership gradually was presented with the opportunity to possibly become involved in frontline networking development. To explain how this happened, it is necessary to return to the times as they were in 2001-2002.

Figure 2: Young woman with wilful reindeer (January 2002)

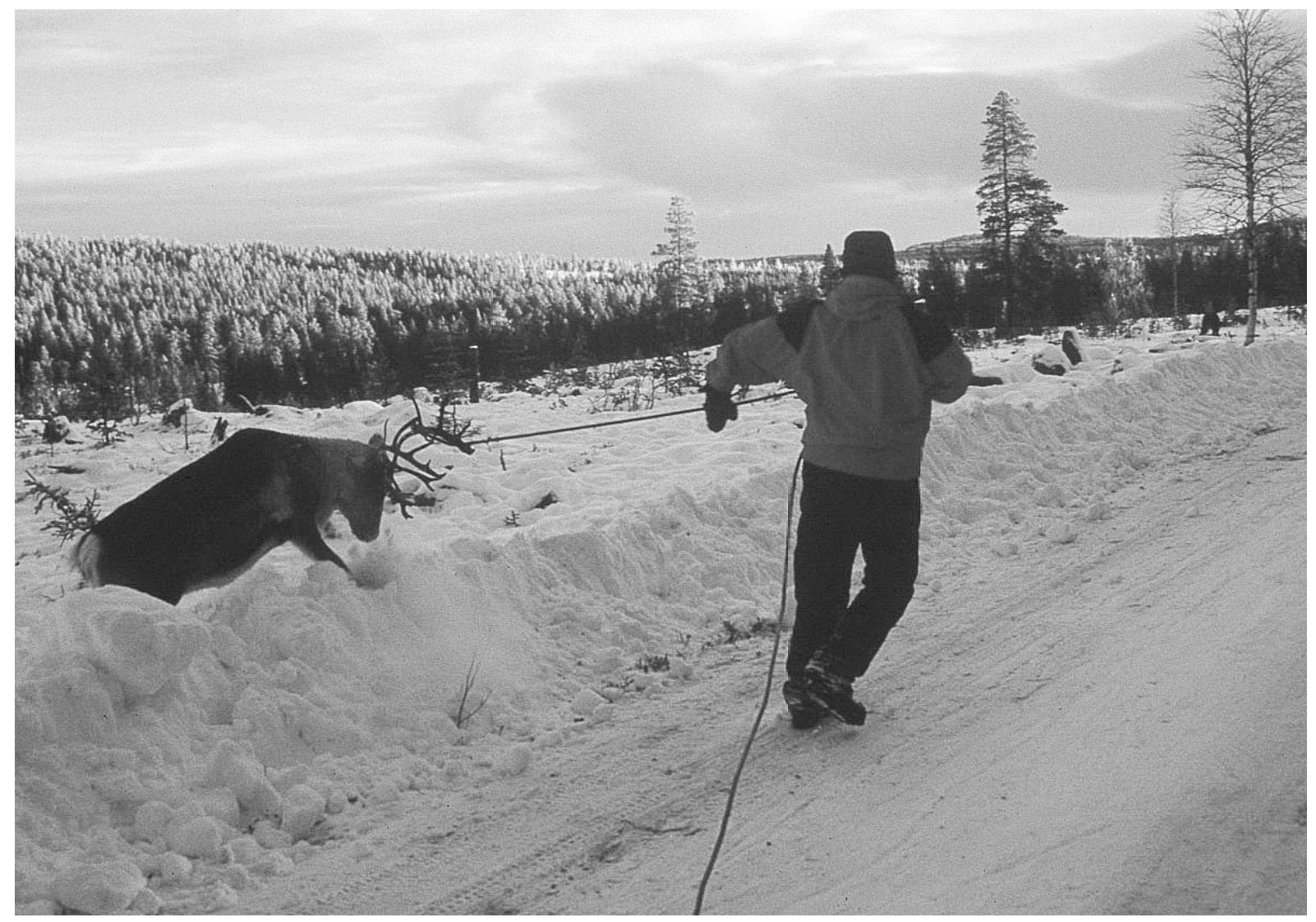

Photo by Lena Kuoljok Lind

Since its introduction, the mobile phone has become much used among the reindeer herders. The coverage is by no means full in the grazing areas, but the Nordic Mobile Telephony (NMT) system had provided a fairly good coverage, even if patchy in the central grazing areas. However, at the time WIS was run, the NMT system was being demounted and the residual GSM system had never provided comparable coverage in the rural areas. The situation was bewildering 
as at the same time there was much upheaval around the $3 \mathrm{G}$ system which was about to be built, accompanied by advertising and public debate praising the applications that were about to become available for mobile use. Only that coverage was not to be expected in the reindeer grazing areas. In sum, the reindeer herders' access to ICTs was diminishing while other sectors and regions in the country became increasingly saturated with access and applications. This was not obviously a matter which a single gender equality project could address. At policy level, the Sámi Parliament obviously discussed with the relevant ministries and authorities. But, would it be possible to take measures locally? For instance, could something be done in co-operation with the local university? The scope of the associated project at LTU included inviting additional LTU divisions and individual researchers to take part in the WIS development activities and suggest further actions. ${ }^{5}$ The idea was to create a dynamic wireless network of peer-to-peer type, made possible by the use of Delay Tolerant Networking (DTN), which at this time was getting established as a new research area. ${ }^{6}$ The idea was to build it from a mix of mobile and (semi-)static nodes - a mix of small scale antennas and laptops or basically any device with wireless capacity. The realisation of the connectivity proposal became a shared goal between the researchers and the two WIS project workers. This was possible thanks to approval by the board of the grazing community, that is, by the owner of the WIS project. $^{7}$

The first part of the N4C project title, "Networking for Communications Challenged Communities", tells about the instrumental aim, which is:

5 A meeting addressing the status and potentials of ICT was arranged, with representatives from WIS, the Sámi village, LTU, and the municipality. Henrik Micael Kuhmunen, principal of the Sámi Educational Centre, was present at the meeting, and he formulated the blunt request to the LTU team: "We want $3 \mathrm{G}$ in the grazing areas." After hearing from colleagues about this request, a visiting networking expert at LTU launched an idea for Internet connectivity that targeted the connectivity problems faced by the community in the grazing territory.

6 The coordination of DTN development is organised by the DTN Research Group, DTNRG (www.dtnrg.org).

7 Towards the end of the WIS project, the process could have taken different turns. With national funding and EU Objective 1 and Interreg North Calotte funding, the ICT initiative went further. The first steps of research were carried out under the name "Sami Network Connectivity" (SNC), and this was also how the dynamic DTN architecture originally launched in 2002 has been labelled. At the time of writing, the process is part of an EU FP7 ICT project with 12 partners in eight countries. The project is called $N 4 C$ or "Networking for Communications Challenged Communities: Architecture, Test Beds and Innovative Alliances". This three-year project started in May 2008. 
"[...] the deployment and testing of ubiquitous and pervasive networking for communications challenged communities in a manner consistent with an overall vision for a future Internet that can encompass not just users and applications in well connected regions, but that can also reach out to rural areas" (cf. N4C Annex I 2008: 3).

The subtitle "Architecture, Test Beds and Innovative Alliances", on the other hand, indicates how the impact of this work is envisioned to come about, namely trough inclusive processes where alliances are created between local communities and members of the global community of ICT experts. This way of working has a background in the so-called Scandinavian tradition of participatory design and can be seen in the context of the recent Living Labs movement (BergvallKåreborn/Ståhlbröst 2009). Other influences for the formation of the project scope include discourses furthered during the World Summit of the Information Society (WSIS) (ITU 2010), community informatics (Gurstein 2000), and the gender and technology studies methodology developed at LTU during the 1990's (Mörtberg 1997; Mörtberg et al. 2003).

WIS was an EU Objective 1 structural funds project, run during 2001-2003, by one of the Sámi villages in Jokkmokk. ${ }^{8}$

The aim of Objective 1 was to

"[...] support the takeoff of economic activities in these regions by providing them with the basic infrastructure they lack, whilst adapting and raising the level of trained human resources and encouraging investments in businesses" (cf. Objective 12010 ).

In Sweden, the Sámi Parliament distributed Objective 1 funding dedicated for the Sámi interests and reindeer husbandry. The European Union's Seventh Framework Programme (FP7) aims to improve and develop the research capacities and capabilities of the Member States. The programme shall "take European research to the forefront" (cf. European Union 2010). From catching up via Objective 1, the effort has thus moved ahead to the European forefront. Several people have at different points been decisive for the process from WIS to N4C.

When assessing this process, it is significant that the WIS project leader took the initiative to seek contact with the regional university. After the communities were challenged by the launch of the DTN solution for communications, in parallel to the university actors seeking research funding, the WIS project team independently of the university actors located additional partners that would be able to make a difference in driving the process. Local actors, includ-

8 In Objective 1 2000-2006, the Structural Funds were directed to regions with particularly low gross domestic product (below $75 \%$ of the Community average). To "qualify", a region had to be characterised by a low level of investment, a higher than average unemployment rate, a lack of services for businesses and individuals, and a poor basic infrastructure. 
ing the Same Net staff based at the Sámi Educational Centre, supported the effort through different measures. The two former WIS staff established a limited company aimed at exploiting ICT solutions for reindeer industry, and from that position they had a significant role in driving the process towards an FP7 application and an established consortium. In parallel to the local activity, university actors and people working in Internet standards organisations and other environments associated with the governance of the Internet were active as well. Without this involvement and drive of expertise, an advanced ICT project like the $\mathrm{N} 4 \mathrm{C}$ project would not have happened. However, there is a reason why an activity has emerged that is directed to Jokkmokk. In sum, the co-operation that started with "Woman in the Sámi Village" continued with a series of projects that brought the SNC proposal further towards realisation. Some of these projects were owned by the university and some by the grazing community (cf. Lindberg/Udén 2008, Lindberg/Udén forthcoming). A milestone was achieved when the functionality of SNC was proven in field tests, providing cached web access and e-mail traffic in the community's summer territory in 2006 (Doria/Udén 2006; Lindgren/Doria 2007; Udén/Doria 2007).

\section{ICT access and location - saturation and shortage in the reindeer nomad experience}

The SNC idea opened the prospect of access to services such as e-mail and the World Wide Web in places where people lived and worked and where today communications or infrastructure are not within reach. The price, if one can speak in such terms, for this robustness was delays. How come this was of interest? Beach (2001) described how Sámi reindeer herders of today use and are affected by modern technology:

\footnotetext{
"The long ski trail left in the snow still speaks of an age-old adaptation as essential to the life of a reindeer herder now as hundreds of years ago. But, should we follow this track, it might well lead us to another trail, a broader one cut by a modern snowmobile, which the Saami call a "scooter", and overhead we might find a great span of cables carrying power from the numerous hydroelectric dams to the towns and cities, railroads and mines" (cf. Beach 2001: 7).
}

Beach's anthropological account was originally printed in a Swedish edition 1993 and written as early as 1975 (cf. Beach 2001: x). Thus, the conditions described anticipate the information technology revolution, at least in so far as its impacts had reached the every-day life in Jokkmokk. To the description by Beach can now be added that as part of the semi-nomadic practice, the herders 
nowadays literally wander between ICT affluent locations and those where access, if available at all, is patchy, limited, and costly. Going by car with a group of herders along the roads in the grazing area, one can note how seemingly suddenly, without warning, they take up their mobile phones from pockets and sacks, turn them on and make a few calls. Repeatedly travelling the same routes, they know the spots that mobile telephone masts reach. This is a new gradient to consider; ICT access has become a constituent of the landscape.

The Swedish national policy to subsidise the deployment of broadband in remote and sparsely populated municipalities has made that also a municipality like Jokkmokk, with 0.03 inhabitants per square kilometre, is "online" today. At least this goes for the municipality centre of Jokkmokk town and the larger villages along the main roads. These (comparatively) large places are often where the Sámi village members have their winter homes. As the address of the winter homes generally is where the community members are registered as residents in national accounting, these members will be included in official statistics as citizens with full access to ICTs as the Internet, fixed and mobile telephony, and television and radio broadcast. Why this affluent state would not be "enough", why DTN development was of interest, or should we say why the statistics are misleading, is a matter of cultural diversity and the fact that the economy of reindeer industry takes place beyond the built environment. As noted above, ICT use was not considered as a major concern in the original WIS development efforts, which can be attributed to the non-presence of these technologies in the herding areas. From a social perspective, one can note that using up-to-date communication options is as attractive for the herders as for any European citizen and small business owner; everyday details need to be sorted out with family, colleagues and business contacts; authorities and public services need to be contacted on behalf of oneself or perhaps an elderly family member or child, and so forth. These people are members of an indigenous community. Nonetheless, one should be aware that all the details that make up citizenship need to be taken care of by the reindeer herders as much as by any citizen who aspires to a sustainable place in society for oneself and ones family.

The ICT access gradient experienced by the herders changes over time. This does not happen, as one could assume in this information society era, in a direction where connectivity and access options are consistently increasing. Throughout the last decades, the community has experienced how new technologies have been deployed and made commercially available only to be pulled out again - out of the area or out of service. This includes, first, the analogue Nordic Mobile Telephony system (NMT) and later its digital replacement. The full depth of the access gradient is perhaps best explained by that even satellite coverage is limited in the Arctic (cf. Beck et al. 2007). Commonly, satellite commu- 
nication is envisioned as the concluding "final option" in otherwise non-access areas. But in combination with the mountainous topography and the lack of infrastructure in the grazing territory, the scarcity of satellites serving the Arctic puts constraints to utilising even this connectivity option. At the other end of the access situation, that is, in the winter homes, the herders may even be able to choose between service providers and means of delivery for Internet access, telephony, television, radio broadcast, and so forth.

\section{$7 \quad$ Knowledge communities - Technical research and development}

As one of the main goals, the N4C project aims to develop a robust access solution for nomadic use where other options do not reach, are too costly or for other reasons impracticable. The nomadic infrastructure is based on wireless links and the evolving Delay Tolerant Networking (DTN) concept (cf. Cerf et al. 2002). As heritage from SNC, the SNC architecture is one of the starting points for the N4C research:

"[The architecture] involves using the DTN bundle protocol to relay data between gateways using opportunistic routing through fixed and mobile relays. The mobile relays periodically travel between the residential communities, meeting at points where data bundles can be exchanged and at locations where gateways to the Internet are available. For use of the system in remote areas intermediate nodes are placed at chosen points. These intermediates are not connected to the Internet but serve to store and forward traffic from/to mobile nodes that pass the node even if not at the same time (passing travellers, hikers, aeroplanes, etc.)" (N4C Annex I 2008: 7). ${ }^{9}$

A main input from the process that started with WIS is the routing protocol PRoPHET, currently a global benchmark in DTN routing (cf. Lindgren et al. 2009). Overall, the networking research around this very northern and remote community has commenced several pioneer steps. The first steps of the chal-

9 To explain the technology shortly, the idea is a network made by portable equipment that can be set up where needed. The traffic is transferred through a peer-to-peer arrangement, and this is made possible by the delay tolerance. Normally, peer-to-peer requires realtime connections, but the DTN technology allows store and forward routines. Wireless routers can be placed strategically to effectively gather the traffic for further transfer. Instead of relying on fixed infrastructure, the traffic is carried by mules. These mules can be for instance PC's or handheld computers with wireless capacity, carried by trackers or placed in boats or helicopters (to mention options that are realistic in the case.) (N4C 2010). Of course, the technology is still in research and development - otherwise it would hardly be the subject of a Seventh Framework project. 
lenge drew together three Swedish universities, and as demonstrated by the above quote, leading American experts have been dialogue partners from the start in 2002. N4C added a leading European environment for DTN research, Trinity College Dublin, to this group. ${ }^{10}$ Two LTU PhD students carry out applied network construction in the herders' lands in each test season. In this work, the team is exposed to conditions that computer scientists and systems developers do not normally have to deal with to any greater extent. In networks put up in the more office type of working place environments, several technicians and engineers have, so to speak, already paved the way for these groups. Civil engineers, construction engineers, builders and architects organise our sheltered, built environments, where such as weather, wind and wild animals do not disturb. Electric power is provided in an orderly manner - at least, in the industrialised world. In the field, or as in this case, under the circumstances in which the reindeer herders work and live, the team must accomplish so much on its own that need not be thought of in the laboratories. If a piece of equipment is placed in nature, nature's fractions and creatures will respond. Condensation damages the circuits. Birds pick on the casings. Trees and leaves grow and change the horizon. When walls, doors, ventilation, heating and climate systems, janitors and cleaners are not around, there are so many more details that require planning, attention and correction along the way. Last but not least: How to organise the provision of power supply? Solar panels are included in the N4C experiments, though their capacity is limited by the Arctic Circle.

The expert and "coming generation" involvement in a small rural population can be described by a common knowledge society definition:

"A new kind of organization is spearheading the phenomenon: knowledge-based communities, i.e. networks of individuals striving, first and foremost, to produce and circulate new knowledge and working for different, even rival, organizations. One sign that a knowledge-based economy is developing can be seen when such individuals penetrate conventional organizations to which their continuing attachment to an external knowledge-based community represents a valuable asset. As members of these communities develop their collective expertise, they become agents of change for the economy as a whole" (David/ Foray 2002: 1).

The N4C process can be described as a meeting between a local community and a knowledge community. Much interest has been paid to the knowledge community by policy makers and others interested in developing economies of different scales. Richard Florida called this group "the creative class", and while

10 At Universidad Politécnica de Madrid, a multi-disciplinary group with expertise in areas such as air-interface technology and robotics is involved. At LTU, as in the other N4C partner universities, PhD students are engaged. 
giving advice to political leaders he stated the need to attract this group to their regions in order to build success (cf. Florida 2002). In the Jokkmokk (or WISN4C) case study, a gender equality project for rural women working in a traditional industry has met with great interest from members of the creative class, or knowledge community, directing their interest to a sparsely populated and remote municipality.

Figure 3: Children are part of the local community meeting the test team members in on-site tests

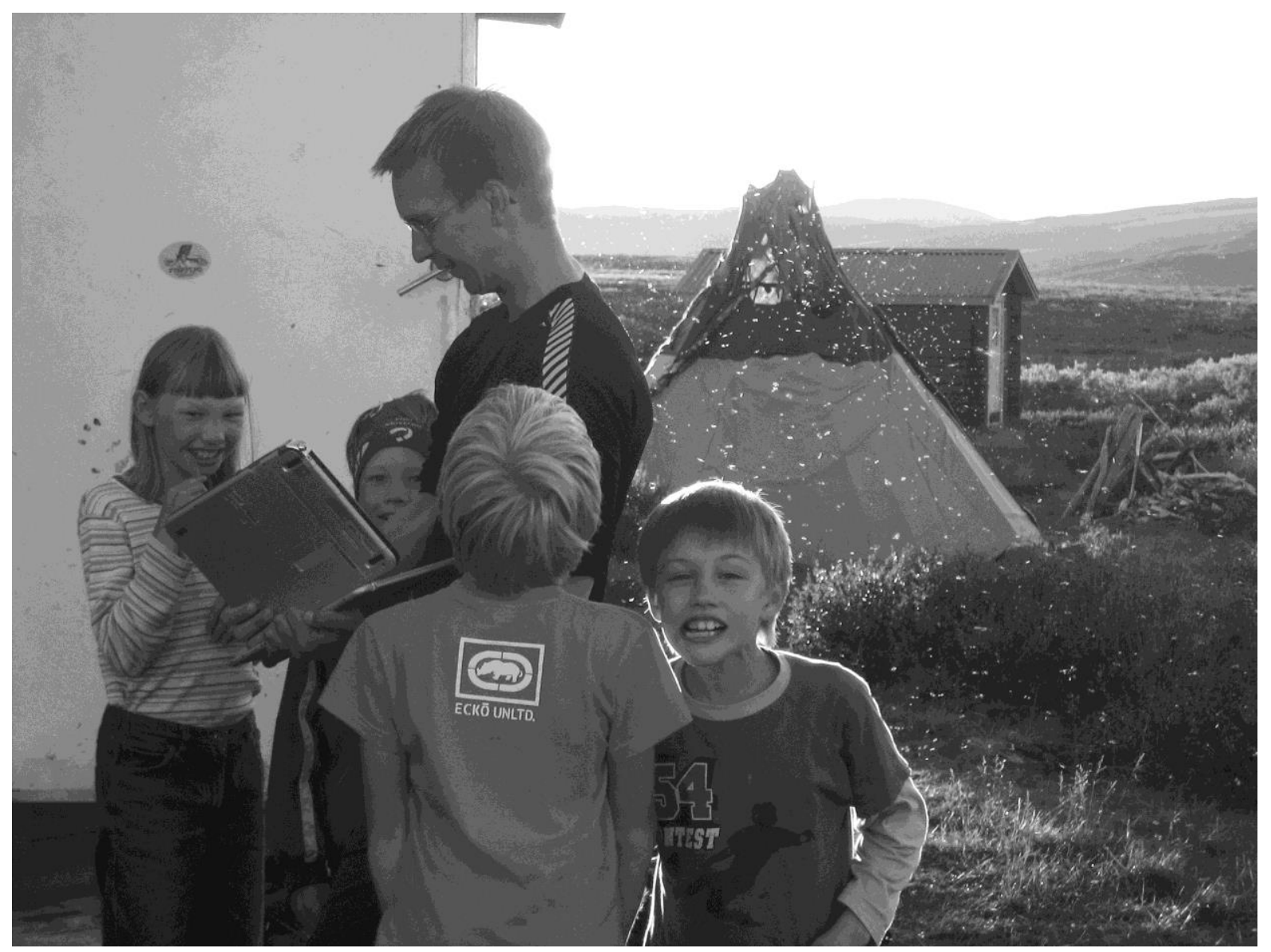

Photo by Luleå University of Technology

\section{Indigenous women leading in the innovative alliance}

Mobile phones are used when the conditions allow, and the Internet has been used by the Sámi via Same Net since before the World Wide Web had gained its present impact. The data at hand also tell that the original WIS staff - the two 
women reindeer herders - in the mid 2000s started a company with a technology-based business idea. This company is now a partner in N4C. A purpose of this company is to refine the animal (reindeer) tracking system which the owners have developed. But this business idea is not the sole involvement the owners have had in the process. Throughout the WIS-N4C process, the original WIS project workers have taken part in and driven several other sub-processes and so communicated the nomadic ICT idea to all - from scientists to neighbours, politicians and civil servants. On different occasions they have visited UN and EU summits and exhibitions, as well as regional and local arrangements. However, among all opportunities that have come about, it is noteworthy that these women have put their main personal investments in a reindeer husbandry application, forming a limited company around it. A number of themes have circulated in the alliance's discourse. These could have been alternative choices. For instance, one of the women is a preschool teacher. Thus, distance education, which is brought up in virtually every thinkable e-inclusion, ICT policy and digital divide discussion, could easily have been their choice, all the more since it has had a place among the gains envisioned as possible through the SNC system. (cf. Doria/Udén 2006).

On several occasions, we who have been involved have asked ourselves if not - to speak with Gurumurthy (2006) - old hegemonies have played a part. After all, there have been moments when both gender and ethnicity have seemed to matter more than the quality of our efforts. The moments when this has perhaps worked to our advantage are of course easier to accept than those when such things have stood in our way. For instance, it has been easy to gain media interest for the efforts. The extent to which such interest has in real terms been helpful for the efforts themselves is not clear however. Though promoting women reindeer herders may have positive connotations in many instances, it is not necessarily possible to conceptually combine ICT development with Sámi women in the context where the Sámi reindeer herders' identity is in real terms constructed (Johansson/Udén 2008; 2010; Lindberg/Udén 2008; Lindberg/Udén forthcoming). Questions about gender, ethnicity and development are important to keep asking. Nevertheless, coming to conclusions is a matter of asking multifaceted questions. Referring to the concerns expressed by Huyer and Hafkin (2007) and shared by many other feminists and gender equality activists in the ICT area that women are at risk of becoming increasingly marginalised in the knowledge society, it can be noted that women are deeply involved in furthering the WIS-N4C process itself and that women gain employment and business opportunities along the way during the research and development process. Gender equality and affirmative action for women have been explicit main goals in a minority of the projects that have made this possible. But it is questionable if 
this gender inclusive process would at all have come about without them. Putting it in simple words, the women reindeer herders have through the WIS-N4C process transformed from supposedly inferior snowmobile drivers (as compared to male herders) to knowledge society entrepreneurs. Affirmative action was the ticket for getting in. The WIS project provided a platform for establishing new contacts.

Has the innovative alliance brought change, either positive or negative, to these SME owners and the other women of the community originally thought of as beneficiaries of WIS? At this point, this is not clear. The leaders of WIS started out as reindeer herders, that is, women in a male-dominated, masculine profession. In the process described here, their situation has remained the same. Furthering the WIS-N4C process, they have stepped into yet more of the same, in a statistically male-dominated, symbolically masculine environment of technical research and development. As owners of a technology-intensive SME start-up that is aimed at exploiting an idea for animal tracking, they combine all these male-dominated worlds: reindeer husbandry and technology R\&D. ${ }^{11}$ It is not obvious how this should be interpreted. Given the above facts, it is possible that the status quo has been kept. This is assumed when the WIS-N4C process is compared to the knowledge economy as described by David and Foray, which is characterised by a growing speed of innovation including both formal and layman environments, as innovation comes close to being the sole means to survive and prosper in highly competitive and globalised economies (cf. David/Foray 2002). Societies as economies are made of people and, if the above holds for "people", should it hold for "women" as well? At the end of the day, not to be ruled out in the fierce competition but simply defend the place one has may be an acceptable reward? Not "all" women in the community have been directly affected by the WIS-N4C process, but those who have been can distribute some of the good that comes out of it in accordance with their own judgements and aims. In their capacity as full reindeer herders, the former WIS leaders are authorised to give the research team access to the herding locations and the meeting with "nature". These partners can offer and decide about resources of tangible value for the research process and its profile among other technical research efforts.

The learning would be that an analysis of how women's situation is affected by knowledge society processes risks to loose valuable information if based on the assumption that women are a homogeneous category. Moreover, taking just one step of differentiation in the analysis will not necessarily give the full pic-

11 For instance, Nutek (2007) has shown that less than $20 \%$ of the public financial business venturing support has been allocated to women entrepreneurs. 
ture, let's say, of "women" and "indigenous women". If the case description would have stopped there, the process could have appeared more fantastic than the more contextualised analysis gives at hand. Are these women just doing something quite corresponding to what they have always done, just that the times have changed so that the context they need to deal with is different? If this suspicion takes some of the glamour out of the case, the insights given by taking the analysis further indeed blur gender and ethnicity as categories in relation to leadership.

\section{$9 \quad$ Access and intersections of culture and location}

A feature of the N4C system is its placement in nature. Basically, it has been created as a means of communication in unsettled areas - for use in the camps of the semi-nomads. In N4C, also capture of meteorological data and applications for hunters and hikers are investigated. In "nature" is also where the tests in the N4C project are carried out - that is, in field tests. This puts the mainstream ICT developer and development team to the test. The key component of this technical solution is not derived from urban settings, but from another very interesting encounter with nature that humans are presently involved in. During the tentative development stage of this technical idea, there was communication between the Department of Computer Science at LTU and the USA-based group that was then in the process of composing the Internet draft where DTN was first specified: Delay-Tolerant Network Architecture: The Evolving Interplanetary Internet (cf. Cerf et al. 2002). The origin of DTN was at its time known as interplanetary networking. The time restraint of the "normal" Internet does not allow the long roundtrips that are inevitable in communication between the earth and, for instance, Mars. As communication between planets and spacecrafts gradually grew into a practical problem, interest rose for automatic computer communication that would be able to handle "delays" (compared to end-to-end connectivity on earth). To those involved in this work, it then became evident that the solution they were working on was of relevance for many terrestrial scenarios as well. The initiative within the community in Jokkmokk and DTN's occurrence met in time. This was manifested in the above mentioned Internet draft, where terrestrial applications of DTN where listed:

"The Sami people in Lapland live in widely dispersed communities in remote areas and are not well served by either wired, fixed wireless, or satellite Internet service. They do, however, frequently travel on snowmobiles from community to community, and congregate at work sites and larger towns. To effectively serve this environment, an architecture is required that can embrace intermittent, probabilistic connectivity, store and forward 
operation, and high and variable delays. (The architecture described in this document meets these needs.)" (cf. Cerf et al. 2002: 11).

Presently, Internet connection is not available to the community while being in the grazing areas. Also mobile phone systems and even radio broadcast are only intermittently available. Speaking with Johnson et al. this is of relevance to the observation that access to and manipulation of the digital economy requires "a well developed, well maintained and affordable information infrastructure" (cf. Johnson et al. 2005: 217). Johnson et al. argue that the digital, "dematerialised" economy is underpinned by a "materialised" infrastructure and that one component in that underpinning is physical addresses of people. A nomadic population challenges the concept of physical addresses - indigenous, traditionally nomadic populations and the "post modern" nomads alike. The difference comes with the infrastructure available in the respective areas where these nomads travel. To a business traveller or "post modern" nomad it may appear as if time, place, and distance have lost their significance with the advent of mobile telephony, wireless networks, and super fast broadband. The meeting with the reindeer nomads brings forth the materiality of networking, the limitations of any technical system and thus the limited extent to which we can indeed be freed from the restraints of time and place, by the mere existence at the abstract level, of oh so appealing solutions. The Sixth Framework Programme Coordination Action "Analysing Broadband Access for Rural Development" (A-BARD) argued explicitly along these lines and expressed the worries that are easily raised when viewing the ICT development from a rural perspective:

"Depending on the definition of what a rural area is, it can be stated that $25-40 \%$ of the
European population still lives outside major cities and towns. New technologies and in-
frastructures for advanced communications are being introduced in towns, cities, and in-
dustrial areas and in certain more fortunate rural areas. All rural areas need comparable
information technology, telecommunications and broadcasting infrastructures to urban
centres if they are to compete for jobs and develop a more balanced economic activity
with diversity of employment. The real danger is that rural areas will increasingly lag be-
hind urban areas. If corrective steps are not taken, enabling ICT systems will tend to con-
centrate in cities and core regions and opportunities for rural revitalisation through the
use of these technologies will continue at a slow pace" (cf. A-BARD 2006: 2).

David and Foray (2002), on the other hand, maintain that the distinction frequently drawn between the information society "haves" and "have-nots" is overly simplified, as is the notion that there has emerged a "digital divide" that can and should be overcome by providing universal technical access to the Internet:

"[...] the more difficult and in a sense more fundamental problems are not simply those of providing greater technological access to information streams. Rather, they involve furnishing people with the cognitive capacities and intellectual frameworks than enable hu- 
mans to interpret, select and utilise information in ways that augment their capabilities to control and enhance the material circumstances and qualities of their existence" (cf. David/Foray 2002: 10).

The WIS-N4C case study cannot confirm such an unconditional assertion. Comparing the routes to knowledge society inclusion laid out by David/Foray and Johnson et al. respectively, the latter identify steps, and an order of steps, that mirror the challenges of the Jokkmokk reindeer herders. First they place ICT and connectivity, followed by usable content and, as third in the list, infrastructure and deliverability. Human capacity is only step four. It is not that David and Foray do not see a role for ICT in the success stories of the knowledge society. In their view, this role revolves around "the capacity of the new information technologies to enable better integration of knowledge through helping bring down the cost of transporting it" (cf. David/Foray 2002: 19). Interestingly, they so provide the explanation of why ICT access also matters in the grazing areas. This is what access in the grazing territory is about: access where information and knowledge are generated and where retrieving information can in real terms make a difference. This is what the quest has been about in the series of projects from WIS to SNC and N4C: better integration of knowledge in reindeer industry, less cost for transporting it.

\section{Knowledge society capacity and access intersectionality}

A Sámi individual may have access in his or her capacity as member of a multiethnical modern society as Sweden. ${ }^{12}$ This situation is experienced by many of the herding families in their winter homes; most likely it is so for the children in school and perhaps for the spouses in their paid employment. This, however, does not give access for the reindeer nomadic culture. In his book about the Jokkmokk herders, Hugh Beach caught the minority situation in a manner that speaks also about the access situation: "Being incorporated into the Swedish social welfare system has given a comfortable life and a future (though maybe not a Saami future)" (cf. Beach 2001: 27). The content in the brackets is the key. ${ }^{13}$

12 Swedish authorities do not register citizens by ethnicity. Therefore, the education level of Sámi cannot be statistically evaluated. But the fact that many Sámi are teachers, engineers, researchers, artists, etc., that is, are members of the creative class, as termed by Richard Florida (2002), should be easily verified. For instance, this goes for the author of this article. Thus, if education comes first, how can the conditions experienced by Jokkmokk's reindeer nomads be explained?

13 In this article, the spelling "Sámi" is used. As other spellings also occur in literature, quotes can contain alternatives, e.g. "Saami". 
The issue of access in the grazing areas can be formulated as a paraphrase of Beach's formulation: The value at stake is not the individuals' future but their Sámi future. The concrete effects of access in terms of infrastructure and connectivity does not negate the power of intangible capital or human intellectual capability demonstrated in this case. The insights and capacities demonstrated by the local actors in Jokkmokk and the Sámi villages show that the local partners have not been passive receivers, informed by the social sciences researchers and ICT experts to become knowledge entrepreneurs in their community. The opportunity for the local-global meeting came through coincidence, one may say, but the viability of the process was prepared at local level. In this respect, the above referred conclusion of David and Foray, that peoples' capacity comes before technology access, is certified. However, this is not such a strong argument that the factor of difference between individual inclusion and the inclusion of cultures can be dismissed. Rather, the WIS-N4C case study would suggest that both factors coincide. Wamala's access intersectionality theory brings the different sides of the coin together (cf. Wamala 2010). Access or non-access is no constant presence or permanent trait that follows the individual. Instead of seeing either/or, we can think of a fluid state of non-access rising from intersections that create moments of access when merging. With this notion, the situation of the herders travelling through a landscape of access gradients is perfectly caught. Wamala also suggests that one dimension of access is that we gain it through others. This is one aspect of the multi-levelled intersections that, when merging, create moments of access. Wamala's example with Nora, the supposed non-user who regularly is an Internet user thanks to that she can find help from others, demonstrates the principle. In the case of WIS-N4C, the scale is different but the principle is the same. None of us have ICT access thanks to our sole, individual accomplishments. Being part of a group or society that organises the prerequisites for its members having ICT access is eventually a term we are all faced with. This becomes obvious through the WIS-N4C process, as the contacts between local actors and knowledge communities have created new ideas on how to technically meet the herders' needs. The reciprocal gain includes the input to Internet design that arise from working on the conditions that the reindeer herders live and work with and that go beyond the built environment. 


\section{References}

A-BARD (2006): Analysing Broadband Access for Rural Development. IST project summary 2005-2006. MAC - The National Microelectronics Applications Centre Ltd (IE) and The European Commission, Information Society Technologies. Action line POLICIES-3.5 Information Society issues

Aas, G.H. (1999). Kvinne-forskningspolitiske (pr)övelser. Licentiatuppsats 1999:54. Luleå University of Technology, Luleå

Amft, A. (2000): Sápmi i förändringens tid. Dissertation. Umeå University, Umeå

Åström, G. (2005). Makt att forma samhället och sitt eget liv - jämställdhets-politiken mot nya mål. Slutbetänkande. Statens offentliga utredningar SOU 2005:26. Stockholm

Beach, H. (2001): A Year in Lapland: Guest of the Reindeer Herders. Washington

Beck, R.; Hinkel, K; Eisner, W; Liu, L. (2007): GPSDTN: Predictive Velocity-Enabled Delay-Tolerant Networks for Arctic Research and Sustainability. Second International Conference on Internet Monitoring and Protection (ICIMP 2007), pp. 34-44

Bergvall-Kåreborn, B.; Ståhlbröst, A. (2009): Living lab: An open and citizen-centric approach for innovation. International Journal of Innovation and Regional Development 1(4), pp. 356-370

Braidotti, R. (2006): Transpositions: On nomadic ethics. Cambridge/Malden

Cerf, V.; Burleigh, S.; Hooke, A.; Torgerson, L.; Durst, R.; Scott, K.; Fall, K.; Weiss, H. (2002): Delay-Tolerant Network Architecture: The Evolving Interplanetary Internet. draft-irtf-ipnrg-arch-01.txt. IPN Research Group, Internet Draft. http://www.ipn sig.org/reports/draft-irtf-ipnrg-arch-01.txt

Cisler, S. (2000): Subtract the Digital Divide. Online Essay. http://home.inreach.com/cis ler/divide.htm (last accessed 07.02.2010)

County Administrative Board of Norrbotten (2010): Facts about Norrbotten. Luleå: County Administrative Board of Norrbotten. http://www.bd.lst.se/fakta/Startpage.aspx (last accessed 04.08.2010)

CroCoPil (2010): CroCoPil concepts. http://www.cdt.ltu.se/projectweb/42c13bdf2e759/Con cepts.html (last accessed 10.05.2010)

David, A.; Foray, D. (2002): Economic Fundamentals of the Knowledge Society. SIEPR Discussion Paper Nr. 01-14. Version revised February 2002. Stanford Institute for Economic Policy Research, Stanford CA. http://ideas.repec.org/p/wop/stanec/02003.html (last accessed 04.08.2010)

Doria, A.; Udén, M. (2006): Indigenous Women in Scandinavia and a Potential Role for ICT. In: Trauth, E. (ed.): Encyclopedia of Gender and Information Technology. Hershey, PA

European Union (2010): European research in action: The Seventh Framework Programme (FP7). http://ec.europa.eu/research/leaflets/fp7/index_en.html (last accessed 10.05.2010)

Florida, R. (2002): The rise of the creative class. New York, NY 
Gunnarsson, E. (2006): The snake and the apple in the common paradise. In: Nielsen, A.K.; Svensson, L. (eds.): Action research and interactive research: beyond practice and theory. Hamburg, pp. 117-142

Gunnarsson, E. (2007): Other sides of the coin: A feminist perspective on robustness in science and knowledge production. International Journal of Action Research 3(3), pp. 349366

Gurstein, M. (Hg) (2000): Community Informatics: Enabling communities with information and communication technologies. Hershey, PA/London

Gurumurthy, A. (2006): ICTs as an Inclusionary Imperative: A Seminar on Gender and Information \& Communication Technologies. Speech given at the United Theological College, Bangalore 14th December 2006. http://www.itforchange.net/resapub.html (last accessed 10.05.2010)

Gustavsson, T.; Johnsson, B. (2000): Kustfiskebefolkningens ekonomi. Fiskeriverkets rapport 2000:1. Göteborg

Hooks, B. (1982): Ain't I a woman: Black women and feminism. London

Huyer, S.; Hafkin, N. (2007): Engendering the Knowledge Society: Measuring Women's Participation. WIGSAT - Women, Knowledge, Technology. Montreal

ITU - International Telecommunication Union (2010): World Summit on the Information Society. Basic information: About WSIS. http://www.itu.int/wsis/basic/about.html (last accessed 12.05.2010)

Jernsletten, J-L.; Klokov, K. (2002): Sustainable reindeer husbandry. The Arctic Council and Tromsö. Troms $\varnothing$

Johansson, A.W.; Udén, M. (2008): A critical perspective on equality and innovation assessment and measurement. Proceedings of the 2008 International Council for Small Business World Conference, June 22-25 2008, Halifax, Nova Scotia, CA

Johansson, A.W.; Udén, M. (forthcoming). A critical perspective on equality and innovation assessment and measurement: The irony of public promotion of innovation. Scheduled to be published in Wang, I.-C. and Zepetnek, S.T. de (eds.): Perspectives on Migration, Nationhood, and Ethnicity. Monograph series of National Sun Yat-Sen University, Taiwan. Kaohsiung

Johnson, C.A.; Ariunaa, L.; Britz, J.J. (2005): Constructing the Pillars of a Knowledge Society: The Challenge of Providing Access to ICTs in Rural Mongolia. In: Libri, 2005, vol. 55 , pp. 216-224

Jordbruksverket (2003): Renägare och renskötselföretag: Rennäringens struktur 1994-2001. Jordbruksverket Rapport 2003:14

Lindberg. M.; Udén, M. (forthcoming): Women, reindeer herding and the Internet. Scheduled to be published as research note in Innovation: The European Journal of Social Science Research

Lindberg, M.; Udén, M. (2008): Kvinnor, renskötsel och Internet: En interaktiv ansats som motor i en innovativ process. In: Johannisson, B.; Gunnarsson, E.; Stjernberg, T. (eds.): Gemensamt kunskapande - Den interaktiva forskningens praktik. Acta Wexionensia nr 149. Växjö, pp. 209-231 
Lindgren, A.; Doria, A. (2007): Experiences from Deploying a Real-Life DTN System. International Conference on Mobile Computing and Networking. In: Proceedings of the Fourth Annual IEEE Consumer Communications and Networking Conference (IEEE CCNC 2007), January 2007, Piscataway, NJ, pp. 217-221

Lindgren, A.; Doria, A.; Davies, E.; Grasic, S. (2009): Probabilistic Routing Protocol for Intermittently Connected Networks. draft-irtf-dtnrg-prophet-02. http://ietfreport.is oc.org/idref/draft-irtf-dtnrg-prophet/ (last accessed 04.08.2010)

Mörtberg, C. (1997): "Det beror på att man är kvinna..." Gränsvandrerskor formas och formar informationsteknologi. Doctoral thesis 1997:12. Luleå University of Technology, Luleå

Mörtberg, C.; Elovaara, P.; Lundgren, A. (eds.) (2003): How do we make a difference? Information Technology, Transnational Democracy and Gender. Luleå University of Technology, Luleå

N4C Annex I (2008): Annex I to Grant Agreement no. Fp7-223994, FP7 ICT-2, Networking for Communications Challenged Communities: Architecture, Test Beds and Innovative Alliances

N4C (2010): www.n4c.eu (last accessed 10.05.2010)

Nordin, Å. (2007): Renskötseln är mitt liv. Analys av den samiska renskötselns ekonomiska anpassning. Umeå University, Umeå

Nutek (2007): Utfall och styrning av statliga insatser för kapitalförsörjning ur ett könsperspektiv. Stockholm

Objective 1 (2010): Objective 1: Supporting development in the less prosperous regions. European Commission: Regional Policy - Inforegio. http://ec.europa.eu/regional_poli cy/objective1/index_en.htm (last accessed 10.05.2010)

Rennäringslagen (1971): Svensk Författningssamling SFS 1971:437. English translation: The Reindeer Husbandry Act. Ministry for Foreign Affairs 1991. The Swedish Government Ministry publications series

Sametinget (2010): Samerna i siffror. http://www.samer.se/servlet/GetDoc?meta_id=1536 (last accessed 10.05.2010)

SCB - Statistiska centralbyrån (2001): Siffror om rennäringen. Detaljerad statistik. Statistiska Centralbyrån, Sámiid Riikasearvii SSR and Jordbruksverket. http://www.rennarings statistik.scb.se/ (last accessed 04.08.2010)

Udén, M. (2004): Nya möjligheter för kvinnor i renskötselföretag: rapport till Sametingets kansli Mål 1 Sápmi Norra. Teknisk rapport 2004:23. Luleå University of Technology, Luleå

Udén, M. (2007): Kan kvinnor vara renskötare? Forskningsrapport 2007:09. Luleå University of Technology, Luleå

Udén, M. (2008): Indigenous women as entrepreneurs in global front line innovations systems. Journal of Enterprising Communities: People and Places in the Global Economy, special issue on indigenous entrepreneurs 2(3), pp. 225-239 
Udén, M. (2009): Public Management, Gender Equality and Women's Situation in Arctic Swedish Fisheries and Reindeer Herding. In: Kafarowski, J. (ed.): Gender, Culture and Northern Fisheries. Edmonton, pp. 171-182

Udén, M.; Doria, A. (2007): Technology producers meeting indigenous users: the case of Sámi Network Connectivity. International Journal of Agricultural Resources, Governance and Ecology (IJARGE), special issue on indigenous cultures and diffusion of innovations 6(6), pp. 693-705

Wamala, C. (2010): Does IT Count? Complexities between Access to and Use of ICTs (Among Urban Farmers in Uganda). Seminar on $18^{\text {th }}$ May 2010, unpublished manuscript. Luleå University of Technology, Department of Human Work Sciences, Division of Gender and technology

Warschauer, M. (2003): Technology and social inclusion: rethinking the digital divide. Cambridge, MA 